\title{
Non communicable diseases and infections refuse to go away despite current knowledge and scientific advances.
}

\author{
James K Tumwine
}

Department of Paediatrics and Child Health, Makerere University College of Health Sciences, P. O. Box 7072, Kampala, Uganda. http://dx.doi.org/10.4314/ahs.v14i1.1

It is a pleasure to welcome you to this first issue of African Health Sciences for 2014. We bring you papers on non-communicable diseases, infections, herbal medicine, reproductive health and medical education. The paper by Adisa and Fakeye ${ }^{1}$, introduces us to an interesting component of patient management in type 2 diabetes, that is, adherence to the medication. More than $75 \%$ of the patients were not aware of the indication for the prescribed medicine. Possible barriers to nonadherence included lack of knowledge, poor attitude, high cost, confusing doze of medicine, and premature discontinuation due to side effects. Saudi authors have studied the impact of mild versus moderate intensity aerobic walking exercise training on markers of bone metabolism and hand grip strength in moderate hemophilia patients'. ${ }^{2}$ On the other hand, Ugandan authors $^{3}$ describe histopathological types of cancer of the esophagus, while Chinese authors ${ }^{4}$ report on the anti-human gastric cancer effect of astragalosides.

Quality of life of patients with cancer has become a critical issue in non-communicable disease management. Chinese workers studied the quality of life in rectal cancer patients with colostomy. ${ }^{5}$ Keeping with Chinese scientists, Chao Ou et $\mathrm{al}^{6}$ report the effect of biloba extract on Cox-2 and GST-Pi in rats with hepatocellular carcinoma risk. They conclude that 'EGb can regulate the expression of GST-Pi, but it can't take an effect on the Cox-2 expression in the liver of HCC risk rats.' Wang ${ }^{7}$ reports on the symptom clusters and quality of life in Chinese patients with lung cancer undergoing chemotherapy, while Nigerian ${ }^{8}$ dentists have an interesting paper on maxillofacial tumors and tumorlike lesions. Most of the tumours were benign and late presentation remains a critical issue.

The next two papers are on mundane subjects vis: removal of metallic objects from tissues ${ }^{9}$ and pterygium recurrence after surgery. ${ }^{10}$ We have emphasized this because foreign bodies and pterygium are quite common, especially in rural Africa. Cameroonian workers report on 'dentofacial injuries in commercial motorcycle accidents' and cost implication of care, ${ }^{11}$ while Feng describes the relationship between the morphology of A-1 segment of anterior cerebral artery and anterior communicating artery aneurysms. ${ }^{12}$ On the other hand Chen and others ${ }^{13}$ have studied the treatment of ruptured cerebellar artery aneurysms. We conclude this section with a seminal paper by Talay $^{14}$ on the value of mean platelet volume in the diagnosis of acute pulmonary embolism.

We bring you very interesting papers on malaria and infections among pregnant women. Sezi ${ }^{15}$ discusses the use of bed nets and indoor house spraying in the control of malaria and argues that bed nets and indoor spraying have been catapulted into "a phenomenon of diminishing returns." Nigerian authors report that herbal medicine, together with artesunate, are effective against Plasmodium berghei malaria. ${ }^{16}$ These two papers are important because of the challenge of rapid emergence of resistance of mosquitoes to chemicals used for spraying and malaria parasite resistance to medications used for prevention and treatment.

Abate in Ethiopia ${ }^{17}$ has studied syphilis among pregnant women and found that the prevalence was highest in the 21-25 age group and that students had the highest risk. The authors call for emphasis on 'education to young people on STI risk behavioral change and partner follow up and notification for exposure to syphilis and treatment.' Hitherto, the burden of CMV amongst pregnant women has remained largely unknown. Nigerian workers ${ }^{18}$ found that $91 \%$ of pregnant women had evidence of CMV infection. Although the HIV status was not mentioned, it is important to regularly screen pregnant women for CMV, especially those who are HIV infected. While measles has been largely eliminated from sub-Saharan Africa, occasional epidemics occur. Kuti et $\mathrm{al}^{19}$ have studied the effect of supplemental measles immunization on cases of measles admitted at the Wesley guild hospital, Ilesa, Nigeria. They found that there was a remarkable reduction in the prevalence of measles cases after the introduction of supplemental immunization activities (SIAs).Zinc is a very important micro-nutrient, especially amongst children where it is involved in boasting immunity against infection. Nigerian workers ${ }^{20}$ report that 98 versus $64 \%$ of the children with pneumonia and without had low zinc levels 
in the blood. This calls for policies for use of zinc in the management of children with pneumonia. Nabukeera and others ${ }^{21}$ report on the ppresentation and outcome of tuberculous meningitis among children: experiences from a tertiary children's hospital.

Tanzanian workers studied the effectiveness of counseling at primary health facilities specifically looking at the level of knowledge of antenatal attendee and their attitude on Prevention of Mother to Child Transmission of HIV in primary health facilities in Dar es salaam, Tanzania. ${ }^{22}$ Peltzer describes the prevalence and factors associated with tuberculosis treatment outcome among hazardous or harmful alcohol users in public primary health care in South Africa ${ }^{23}$, while Cameroonian authors report activities of selected medicinal plants against multi-drug resistant Gramnegative bacteria. ${ }^{24}$

Chinese researchers assess the in vitro evidence of baicalein's inhibition of the metabolism of zidovudine, ${ }^{25}$ while Nigeria workers report the haematological, hepatic and renal functions of petroleum tanker drivers in Lagos, ${ }^{26}$ Nigeria. In vitro evidence for endocrine-disrupting chemical (EDC)'s inhibition of drug metabolism ${ }^{27}$, and correlation between the cystathionine- $\gamma$-lyase (CES) and the severity of peptic ulcer disease ${ }^{28}$ are two key physiology/biochemistry papers with potential practice impact. Turkish authors review locomotor differences in Mongolian gerbils with the effects of midazolam administration in the form of eye drops ${ }^{29}$ while a review of the chemistry and pharmacology of 7-methyljugulone ${ }^{30}$ and the influence of bile acids homeostasis by cryptotanshinonecontaining herbs ${ }^{31}$ completes this section.

June Bardy ${ }^{32}$ has written for us a beautiful piece on sponsorship and gifts from formula companies while Karatas has written for us on the evaluation of chromosomal abnormalities and common trombophilic mutations in cases with recurrent miscarriage ${ }^{33}$ while Aliku $^{34}$ presents a a case of anomalous origin of the left coronary artery presenting with acute myocardial infarction and cardiovascular collapse. How medical education can contribute towards the reduction of maternalmortalityin Angola ${ }^{35}$,burnoutand psychological distress among nurses ${ }^{36}$ in a Nigerian tertiary health institution are seminal papers needing our attention.. The next set of papers concern women and children..$^{37,38}$ We conclude this series with two submissions on the importance of the mean platelet volume in the diagnosis of supraventricular tachycardia, ${ }^{39}$ and the relationship between RDW levels and atrial fibrillation in hypertensive patient. ${ }^{40}$

\section{References:}

1. Adisa R, Fakeye TO. Treatment non-adherence among patients with poorly controlled type 2 diabetes in ambulatory care settings in southwestern Nigeria $A f r$ Health Sci 2014;14(1):1-10.

2. Al-Sharif A-G, Al-Jiffri OH, Abd El-Kader SM, Ashmawy EM. Impact of Mild versus Moderate Intensity Aerobic Walking Exercise Training on Markers of Bone Metabolism and Hand Grip Strength in Moderate Hemophilic A Patients. Afr Health Sci 2014;14(1):11-16. 3. Alema ON, Iva B. Cancer of the esophagus: histopathological sub-types in northern Uganda. Afr Health Sci 2014;14(1):17-21.

4. OuYang Y, Huang JH, OuYang ZT, Kang J. Enrichment and purification process of astragalosides and their anti-human gastric cancer MKN-74 cell proliferation effect. Afr Health Sci 2014;14(1):22-27.

5. Yang X, Li Q, Zhao H, Li J, Duan J, Wang D, et al. Quality of life in rectal cancer patients with permanent colostomy in Xi'an Afr Health Sci 2014;14(1):28-36.

6. Ou C, Zheng H, Su J, Cao J, Li G J, Li L-Q. Effect of Ginkgo biloba extract on the expressions of Cox-2 and GST-Pi in rats with hepatocellular carcinoma risk. Afr Health Sci 2014;14(1):37-48.

7. Wang D, Fu J. Symptom clusters and quality of life in China patients with lung cancer undergoing chemotherapy. . Afr Health Sci 2014;14(1):49-55.

8. Bassey GO, Osunde OD, Anyanechi CE. Maxillofacial tumors and tumor-like lesions in a Nigerian teaching hospital: an eleven year retrospective analysis. Afr Health Sci 2014;14(1):56-63.

9. Ceylan MF, Guner S, Ediz L, Unsal SS, Isik D. Removal of metallic foreign bodies embedded in soft tissues by stereotaxic approach. Afr Health Sci 2014;14(1):64-71.

10. Anguria P, Ntuli S, Carmichael T. Young patients' age determines pterygium recurrence after surgery. Afr Health Sci 2014;14(1):72-76.

11. Agbor AM, Azodo CC, Ebot EB, Naidoo S. Dentofacial injuries in commercial motorcycle accidents in Cameroon: pattern and cost implication of care. Afr Health Sci 2014;14(1):77-82.

12. Feng W, Zhang L, Li W, Zhang G, He X, Wang G, et al. Relationship between the morphology of A-1 segment of anterior cerebral artery and anterior communicating artery aneurysmsi. Afr Health Sci 2014;14(1):8388.

13. Chen Z, Li L, Gong F, Wang W. Endovascular 
treatment of ruptured distal posterior inferior cerebellar artery aneurysms: report of 11 cases Afr Health Sci 2014;14(1):89-93.

14. Talay F, Ocak T, Alcelik A, Erkuran K, Akkaya A, Duran A, et al. A new diagnostic marker for acute pulmonary embolism in emergency department: mean platelet volume. Afr Health Sci 2014;14(1):94-99.

15. CL S. The phenomenon of diminishing-returns in the use of bed nets and indoor house spraying and the emerging place of antimalarial medicines in the control of malaria in Uganda. Afr Health Sci 2014;14(1):100-10. 16. Adegbolagun O, Emikpe B, Woranola IO, Ogunremi Y. Synergistic effect of aqueous extract of Telfaria occidentalis on the biological activities of artesunate in Plasmodium berghei infected mice. . Afr Health Sci 2013;13(4):970-76.

17. Assefa A. A three year retrospective study on seroprevalence of syphilis among pregnant women at Gondar University Teaching Hospital, Ethiopia. Afr Health Sci 2014;14(1):119-24.

18. Hamid KM, Onoja AB, Tofa UA, Garba KN. Seroprevalence of cytomegalovirus among pregnant women attending Murtala Mohammed Specialist Hospital Kano, Nigeria. Afr Health Sci 2014;14(1):125-30.

19. Bankole KP, Ademola AS, Oyeku OA. Effects of supplemental measles immunization on cases of measles admitted at the Wesley guild hospital, Ilesa, Nigeria. Afr Health Sci 2014;14(1):131-35.

20. Ibraheem RM, Babatunde AWRJ, Abdulkarim AA, Biliaminu SA. Serum zinc levels in hospitalized children with acute lower respiratory infections in the north-central region of Nigeria. Afr Health Sci 2014;14(1):136-42. 21. Barungi NN, Wilmshurst J, Rudzani M, Nuttall J. Presentation and outcome of tuberculous meningitis among children: experiences from a tertiary children's hospital Afr Health Sci 2014;14(1):143-49.

22. Wangwe PJT, Nyasinde M, Charles DSK. Effectiveness of counseling at primary health facilities: Level of knowledge of antenatal attendee and their attitude on Prevention of Mother to Child Transmission of HIV in primary health facilities in Dar es salaam, Tanzania. Afr Health Sci 2014;14(1):150-56.

23. Peltzer K, Louw JS. Prevalence and factors associated with tuberculosis treatment outcome among hazardous or harmful alcohol users in public primary health care in South Africa. Afr Health Sci 2014;14(1):157-66.

24. Tchana MES, Fankam AG, Mbaveng AT, Nkwengoua ET, Seukep JA, Tchouani FK, et al. Activities of selected medicinal plants against multi-drug resistant Gram-negative bacteria in Cameroon. Afr Health Sci
2014;14(1):167-72.

25. Wang Y-C, Yang H-Y, Kong L-T, Yu F-X. In vitro evidence of baicalein's inhibition of the metabolism of zidovudine (AZT). Afr Health Sci 2014;14(1):173-77.

26. Awodele O, Sulayman AA, Akintonwa A. Evaluation of haematological, hepatic and renal functions of petroleum tanker drivers in Lagos, Nigeria. Afr Health Sci 2014;14(1):178-84.

27. Li W-P, Wang Y-F, Gao J, Yu M-L, Tu Y-Y, Yao Y-Q. In vitro evidence for endocrine-disrupting chemical (EDC)'s inhibition of drug metabolism. Afr Health Sci 2014;14(1):185-88.

28. Chen X, Wan Y-C, Guo T, Xu C-X, Wang F. Correlation between the cystathionine-r-lyase (CES) and the severity of peptic ulcer disease. Afr Health Sci 2014;14(1):189-94.

29. Akkaya A, Tekelioglu UY, Demirhan A, Erdurmus $\mathrm{M}$, Apuhan T, Bayir H, et al. Locomotor differences in Mongolian gerbils with the effects of midazolam administration in the form of eye drops. Afr Health Sci 2014;14(1):195-200.

30. Mbaveng AT, Kuete V. Review of the chemistry and pharmacology of 7-methyljugulone. Afr Health Sci 2014;14(1):201-05.

31. Gao C, Ma T, Pang L, Xie R. The influence of bile acids homeostasis by cryptotanshinone-containing herbs. Afr Health Sci 2014;14(1):206-10.

32. Brady JP, Srour L. India, Laos and South Africa reject sponsorship and gifts from formula companies. Afr Health Sci 2014;14(1):211-15.

33. Karatas A, Eroz R, Albayrak M, Ozlu T, Cakmak B, Keskin F. Evaluation of chromosomal abnormalities and common trombophilic mutations in cases with recurrent miscarriage. Afr Health Sci 2014;14(1):216-22.

34. Aliku TO, Lubega S, Lwabi P. A case of anomalous origin of the left coronary artery presenting with acute myocardial infarction and cardiovascular collapse. Afr Health Sci 2014;14(1):223-27.

35. Mendes M, Barbosa J, Loureiro E, Ferreira MA. How medical education can contribute towards the reduction of maternal mortality in Angola: the teaching/ learning process of Gynecology and Obstetrics. Afr Health Sci 2014;14(1):228-36.

36. Okwaraji FE, Aguwa EN. Burnout and psychological distress among nurses in a Nigerian tertiary health institution. Afr Health Sci 2014;14(1):237-45.

37. Eze CU, Agwu KK, Ezeasor DN, Agwuna KK, Aronu AE. Sonographic determination of spleen to left kidney ratio among Igbo school age children of south east Nigeria. Eze CU, Agwu KK, Ezeasor DN, Agwu- 
na KK, Aronu AE. Afr Health Sci 2014;14(1):246-54. 38. Mithra P, Unnikrishnan B, Rekha T, Nithin K, Mohan $\mathrm{K}$, Kulkarni V, et al. Compliance with iron-folic acid (IFA) therapy among pregnant women in an urban area of south India Afr Health Sci 2014;14(1):255-60.

39. Ocak T, Erdem A, Duran A, Tekelioğlu ÜY, Öztürk S, Ayhan SS, et al. The importance of the mean platelet volume in the diagnosis of supraventricular tachycardia. Afr Health Sci 2014;14(1):261-66.

40. Sarıkaya S, Şahin Ş, Akyol L, Börekçi E, Yılmaz YK, Altunkaş F, et al. Is there any relationship between RDW levels and atrial fibrillation in hypertensive patient? Afr Health Sci 2014;14(1):267-72. 